\title{
LES SEPULTURES BOGOMILES DE VADU ANEI
}

Silviu Oța

\section{MORMINTELE BOGOMILE DE LA VADUL ANEI}

\section{Rezumat}

În ceea ce priveşte dispunerea planimetrică în cadrul cimitirului, mormintele atribuite bogomililor nu ocupă un loc anume, fiind răspândite printre celelalte complexe funerare. Faptul că au fost descoperite în cele mai diverse locuri în necropolă, fără a respecta o regulă anume, indică faptul că aceste persoane au făcut parte din comunitatea aceasta încă de la început şi au rămas acolo până în momentul încetării utilizării necropolei. Un alt argument în favoarea acestei afirmații îl constituie datarea cu monede care este observabilă de la sfârşitul secolului XV (monedă emisă cândva în anii 1458-1590, găsită în M.263) până în cel de-al treilea sfert al secolului XVI.

În viitorul teritoriu al Țării Româneşti, obiceiul înmormântării cu unul sau ambele brațe flectate din cot, cu palmele aduse pe umeri, la clavicule sau la gât nu este atestat până în secolul XIV. Aceasta se poate datora şi stadiului cercetărilor arheologice. Obiceiul, pentru teritoriul dintre Carpaţi şi Dunăre, nu este atestat la populațiile nomade de stepă. Pentru perioada mai târzie, astfel de morminte a fost semnalate la Oraşul de Floci (în necropola de pe grindul nr.3), Buzău, Cernica, Dumbrava, Străuleşti, Portăreşti, zona Bucureştiului şi a Cîmpulungului.

Situaţia este asemănătoare şi în teritoriul de la este de Carpaţi (viitorul stat medieval Moldova), unde au fost găsite astfel de morminte: Traian (Zăneşti, jud. Bacău), Trifeşti, Hudum (două necropole), Vornicenii Mari. Isaccea.

În Dobrogea, astfel de morminte au fost descoperite la Păcuiul lui Soare, Garvăn, Enisala, Nufăru,

În Transilvania, au fost semnalate de asemenea morminte în care defuncții au fost depuşi cu unul sau ambele brațe flectate din cot, cu palmele aduse la umeri. Aici mormintele în mare parte sunt mai timpurii, dar sunt şi foarte rare. În stadiul actual al cercetării, prezenţa unor astfel de morminte în necropole de tip Ciumbrud, în Slovacia sau Ungaria trebuie analizate cu mare atenție.

Dat fiind faptul că la nordul Dunării obiceiul aşezării defunctului în mormânt cu unul sau ambele brațe flectate din cot şi cu palma adusă pe umăr sau la gât este cel mai bine observabilă cronologic, planimetric şi din punct de vedere al obiceiurilor de înmormântare în cimitirele studiate în Banat, consider că este necesară o paralelă între descoperirile de aici şi cele din situl de la Vadul Anei. Aceasta cu atât mai mult cu cât, în Banat, se poate stabili şi o cronologie a pătrunderii bogomililor sau a principalelor momente în care aceştia au pătruns ori au activat.

În teritoriul vecin, în Banatul românesc, morminte în care brațele defuncților erau flectate din cot, cu palmele aduse în regiunea gâtului, pe umeri sau pe clavicule au apărut în 14 necropole (Ilidia-Cetate, Gornea-Târcheviş̦te, Ciclova Română-Morminți, Gornea-Căunița de Sus, Cuptoare-Sfogea, Gornea-Pod Păzărişte, Gornea-Ogaşul lui Udrescu, Ilidia-Oblița, Nicolinț-Râpa Galbenă, Pojejena-Nucet, ReşiţaOgăşele, Cârnecea-Dealu Bisericii, Berzovia-Pătruieni, Şopotu Vechi-Mârvilă). Din 43 de morminte (unul este dublu). Toate cimitirele se găsesc pe teritoriul actual al județului Caraş-Severin. Mormintele au fost găsite atât în necropole cu biserică, dar şi fără. Asupra defuncților care au avut brațele flectate din cot cu palmele aduse pe clavicule sau la gât s-au emis două ipoteze. Prima dintre ele este aceea că este vorba de practici rituale de dinainte de înmormântare cu scopuri antivampirice şi a fost legată în special de credințe ale slavilor. $\mathrm{O}$ a doua teorie este cea potrivit căreia aceste morminte aparțin unor persoane de credință bogomilă răspândită la nordul Dunării în special din secolul XI. Sub-variante ale acestei poziții a brațelor au mai fost înregistrate la Hodoni-Pocioroane, Obreja-Sat Bătrân, Vojlovica-Humka Azotara (Banatul iugoslav), Kiszombor-B, Szőreg-Homokbánya (Banatul maghiar, comitatul Csongrád).

În general, literatura românească cu privire la erezia bogomilă este destul de săracă şi contradictorie. Cea mai mare parte a literaturii este de natură teologică sau filozofică. Doar într-o foarte mică măsură suntem 
în fața unor studii redactate de către arheologi sau istorici. Aceştia din urmă, cu puține excepții, se feresc în general să atribuie anumite complexe funerare populației eretice, indiferent de originea sa.

Din punct de vedere al interpretărilor istoricilor români asupra problemei ereticilor în spațiul actual al României au existat diverse variante. De exemplu, A. Balotă, consideră că bogomilismul este vorba mai degrabă de o cultură apărută în teritoriul actual al Bulgariei, „mai aproape de masele populare, de aspirațiile lor, de preocupările lor". În timp, "...sub presiunea ideologiei oficiale creştine a statului şi bisericii feudale, a primit o pecete creştină" cu o tentă "...ostilă culturii marilor feudali, a clerului înalt şi a mănăstirilor". Studiile apărute în perioada postbelică şi până în 1989 în bună parte au încercat să justifice lupta populației împotriva feudalilor şi a bisericii chiar dacă sunt recunoscute conjuncturile care au dus la apariția ereziei la sudul Dunării.

Alți istorici s-au preocupat de locul de unde au pătruns la nordul Dunării, precum şi de zonele unde s-au stabilit (vezi craşovenii şi cei din zona Braşov).

Pe teritoriul Țării Româneşti, nu este menționat un document expres cu privire la emigrarea unor eretici bogomili, dar este de bănuit că printre grupurile de populație colonizate aici de la sudul Dunării, trebuie să fi fost şi eretici. Date exacte asupra etapelor de migrare a sârbilor şi bulgarilor în teritoriile nord dunărene provin din sursele istorice târzii. Dacă pentru secolele XIV-XVI se pot identifica pe alocuri zonele lor de stabilire, pentru secolele XII-XIII, ştim doar că probabil au trecut şi la nordul fluviului ca urmare a persecuțiilor religioase.

Sursele literare de după secolul X, redactate la nordul Dunării sunt extrem de sumare. Acestea se rezumă de fapt la o singură scriere, cea a episcopului de Cenad, Gerard şi a fost datată în prima jumătate a secolului XI. Aceasta nu se referă însă la modul de depunere a defunctului în groapă. În aceste condiții identificarea în teren a mormintelor bogomile este mai degrabă ipotetică. Dacă la sudul Dunării se consideră că sfârşitul secolului XIV este data superioară la care sunt semnalate elemente eretice încă active, nu aceeaşi este situația la nordul fluviului. În mod normal, ei nu au mai reprezentat o forță, dar se pot surprinde manifestări târzii ale lor.

În veacul XVII prezența lor este încă semnalată documentar în zona de munte a Banatului, la Caraşova, în regiunea Lipovei, Timişoarei şi a Jenopolei. În general, istoricii consideră că ar trebui mai degrabă căutați din punct de vedere arheologic, ei putând fi identificaţi prin ritualul specific de înmormântare sau prin monumentele funerare. Probabil că situația a fost similară şi în regiunea Țării Româneşti, unde sunt semnalate pătrunderi de populație sârbă şi bulgară.

Un prim element care a atras atenția arheologilor, constă în poziția brațelor care le aveau defuncții în morminte. O identificare primară a fost aceea a depunerii brațelor flectate din cot cu palmele aduse pe umeri, la gât sau pe clavicule. Această practică nu spune însă nimic despre eventuala apartenență a mortului la o sectă sau alta, ci doar că suntem în fața unor practici rituale, altele decât cele obişnuite. Plecând de la acest element, în coroborare cu datele istorice, am încercat într-un studiu mai vechi să disting etapele în care au pătruns ori s-au manifestat aceşti posibili eretici pe teritoriul Banatului.

Un alt indiciu care poate fi un argument în favoarea faptului că suntem în fața unor persoane care este posibil să aibă anumite cunoştințe asupra religiilor dualiste ar fi acele descoperiri de complexe funerare în care s-au găsit inele decorate cu o pentagramă. Ele sunt frecvente în secolele X-XI în tot sudestul Europei (în Ungaria la Szöreg-Homokbánya, Kiszombor-B, în Bulgaria la Hisar, Dălgopol, în fosta Iugoslavie, ca de exemplu la Donji Milanovac, Mačvanska Mitrovica, în România la Capidava, Piatra Frecăței, Dinogeția, Păcuiul lui Soare).

În ceea ce priveşte cronologia acestor morminte, de pe teritoriul actual al României, putem spune că în mod sporadic sunt întâlnite astfel de complexe funerare încă din secolul XI, dar frecvența lor este extrem de redusă. O dată cu secolul XII, acest tip de înmormântări nu mai constituie o raritate şi pentru multe cimitire este chiar o constantă. În funcție de durata de utilizare a unui cimitir, obiceiul flectării unuia din brațe, sau a ambelor cu palmele aduse pe umeri sau la gât este relativ constant. Limita cronologică superioară sesizată pentru aceste practici, o constituie secolul XVII. Cercetările arheologice viitoare vor putea aduce mai multe clarificări în legătură cu aceste tipuri de practici funerare.

De asemenea trebuie spus că în decursul evului mediu au fost identificate în Europa de sud-est mai multe erezii de factură gnostică. Pe baze arheologice sau documentare nu putem face însă diferențe între diversele secte, unde s-au aşezat şi ce obiceiuri funerare au practicat.

Pe plan internațional, chiar dacă literatura este ceva mai bogată, ea reia în general aceleaşi problematici. Din punct de vedere arheologic, opiniile sunt divergente asupra identificării mormintelor 
care pot fi atribuite acestor eretici. Lor le-au fost atribuite la un moment dat, în special monumentele funerare din spațiul fostei Iugoslavii, ca apoi să se revină şi să fie contestată această interpretare.

Cuvinte cheie: mormânt, necropole, bogomili

Mots clef: sépulture, nécropole, bogomiles

Dans la nécropole de Vadul Anei, du point de vue du rituel funéraire, se distingue la présence d'un lot de complexes funéraires qui ont des caractéristiques distinctes du reste des sépultures. Ce qui les différence de la plus grande partie des enterres, est la position différentes des bras (fléchis du coude, avec les paumes misent sur les épaules ou dans le région du cou).

Des 446 sépultures étudiées, 53 ont cette caractéristique.

En ce qui concerne la déposition planimétrique dans la nécropole, elles n'occupent pas une certaine place, étant répandues par mis les autres sépultures. Le fait qu'elles ont été découvertes dans les plus divers endroits de la nécropole, sans respecter une certaine règle, indique le fait que ces personnes ont fait partie de la dite communauté des le commencement et elles sont resté la bas jusqu'au moment quant l'utilisation de la nécropole a cessé. Un autre argument en faveur de cette affirmation est la datation avec des monnaies qui est observable des la fin du XV-e siècle (monnaie émise entre les années 14581590 , et découverte dans M.263) jusqu'au troisième quart du XVI-e siècle.

Les types d'enterrements. Dans 50 de complexes il s'agit d'enterrements singuliers. En trois cas (M.270-271, 332-333 şi 389+395), les enterrements ont été doubles (dans la nécropole de Gornea-Țârchevişte il y a une sépulture double, les deux squelettes ayant les bras fléchis du coude, avec les paumes sur les épaules). On doit faire mention que dans un cas, M.332-333, à un squelette on n'a pas pu préciser la position des bras, s'agissant d'un enfant.

L'orientation des sépultures est en fonction de la saison quand on a fait l'inhumation. OSO-ENE, SSO-NNE (deux) et inconnue pour autre quatre. D'après les calcules faits par M. Rejholkova (Rejholková 1995), l'orientation OSO-ENE est typique pour les enterrements faits au printemps tardif et en été.

Les profondeurs où on été faits les enterrements se trouvent entre $0,25-0,95 \mathrm{~m}$.

\section{Le sexe et les groupes d'age}

Enfants. Comme une première observation, est celle que le nombre d'enfants est assez réduit (11 sujets). Par groupe d'age, on observe qu'il s'agit d'indivis Infans I (M.80, 271, 319, 442), Infans II (M.59, 194, 289) et adolescents (M.100, 150, 298, 336). Leur nombre représente $19,64 \%$ du total des sépultures que nous supposons être des bogomiles.

Du premier groupe d'age, seulement une sépulture avait un inventaire funéraire (M.271), boucle d'oreille et monnaie (émise entre 15121520), le reste de trois étant sans inventaire funéraire.

Le deuxième groupe d'age (Infans II), est un peu plus riche en ce qui concerne l'inventaire funéraire, mais il est du même type (monnaies, boutons, boucle d'oreille). Les monnaies, à une seule exception (M.59, qui peut être fixé pendant le troisième quart du XVI-e siècle) date très largement la sépulture 289 (1520-1566).

Le troisième groupe d'age (Adolescents) se compose de quatre sépultures, mais seulement une contenait un inventaire funéraire (M.100) et elle appartenait à une fillette.

Il est possible que dans les sépultures qui contenaient comme inventaire funéraire des boucles d'oreille, se trouvaient des filles. Pour celles qui n'avaient pas un inventaire funéraire, ou en avait un neutre, nous ne pouvons pas faire des observations en ce qui les concerne.

$\mathrm{Du}$ point de vue de la déposition planimétrique, on ne constate pas une certaine règle. 
Nous pouvons croire que les sépultures d'enfants ou d'adolescents avec ces positions des bras provenaient des familles des quel au moins un des parents ont été des pratiquants de cette religion, probablement des bogomiles. En comparaison avec les autres sépultures d'enfants qui n'on pas été inhumés avec ces positions des bras, on ne constate pas des différences au niveau de la présence de l'inventaire funéraire.

Les adultes. De ces sépultures, seulement en quatre cas a été déterminé le sexe (M.31, 62, 159 sont de mâles et M.117 de femme). Leur inventaire est très pauvre, des monnaies, bagues, boutons et seulement deux fois des boucles d'oreille (M.313, 349).

La déposition dans la fosse des défunts s'est fait dans la position decubit dorsal.

a. La position des bras est connue en trois variantes:

1) avec les deux bras fléchis du coude et les paumes sur les épaules (M.18, 77, 255, 273, $275,298,312,318,320,356)$

2) avec la main droite fléchi du coude et la paume sur l'épaule (M.31, 62, 80, 81, 100, $117,144,150,189,194,271,283,289,319$, $315,336,338,345,349,353,357,367,380$, $382,389,393,395,427,431,442$ )

3) avec la main gauche fléchi du coude, et la paume sur l'épaule (M.30, 59, 150, 153, 159, 167, 184, 193, 195, 295, 313, 330, 333, 342)

b. La position des pieds chez 53 squelettes est étendue. En trois cas on constate d'autres situations, c'est-à-dire :

1) les fémurs coupés et remis en position anatomique normale.

2) le squelette de M.59 avait les genoux très proches.

3) en M.336 le défunt a été déposé dans la fosse avec les pieds fléchis du droit des genoux vers la droite.

La forme des fosses pour ce lot de complexes funéraires est inconnue.

Le mobilier funéraire est extrêmement pauvre pour ce lot de sépultures et il est représenté seulement par un cercueil découvert dans M.345.
L'inventaire funéraire (Les pièces d'inventaire récupérées des sépultures, du point de vue de la typologie et de la chronologie sont analysées dans le chapitre dédié aux parures)

Du point de vue des parures ou des accessoires de port, chez ces sépultures, on n'observe pas des différences, entre celles-ci et le reste des complexes funéraires. Les seules différences en rapport avec les autres sépultures de la nécropole, consistent dans la position des bras. La même situation se rencontre aussi chez des sépultures du Banat, soi quelles sont plus anciennes, soi quelles appartiennent à un intervalle chronologique plus proche (le $\mathrm{XV}$-e siècle) en comparaison avec celles de Vadul Anei.

Pour le futur territoire de la Valachie, l'habitude d'enterrement avec un ou les deux bras fléchis du coude, avec les paumes sur les épaules, aux clavicules ou au cou n'est pas attestée jusqu'au XIV-e siècle. Cela est possible aussi à cause du stade de la recherche archéologique. Les plus nombreuses sépultures fouillées appartiennent aux populations nomades des steppes, et chez celles-ci l'habitude n'existe pas (Ioniță 2004, p. 461481). Pour une époque plus tardive, des pareilles sépultures ont été signalées à Oraşul de Floci (dans la nécropole du grind no.3) (Coman, Rența, Matei, Oța 2003, p. 49, 50, 52, 55, Pl.II), Buzău (Drâmbocianu 1978, p. 29). Il s'agit de M.9, datée avec une monnaie, denier émis en 1558.), Cernica (Cantacuzino 1963, Fig.2, p. 375, 378-379, 381, 382, 383, Fig.17/14, p. 385, Fig.18/1-2, Cantacuzino 1981, p. 212, 223, 224, 227-228, 231), Dumbrava (Diaconescu, Mihăescu 1982 (1986), Fig.3, M.8, 13), Străuleşti (Cantacuzino 1963, p. 375), Portăreşti (Tătulea 1981, p. 48, 50, 51, Fig. 4/3-M.8, Fig.4/11-M.24, 55), la zone de Bucarest (Ştefănescu 1981, p. 276) et du Cîmpulung (Trohani 1982, p. 253, Cantacuzino 1998, p. 186, Fig.3, p. 187, 189, Fig.4).

La situation est semblable aussi dans le territoire de l'est des Carpates (le futur état médiéval La Moldavie), où ont été découvertes des pareilles sépultures: Traian, Zăneşti, dép. Bacău (Cantacuzino 1963, p. 375), Trifeş̧ti (Ioniță 1962, p. 737), Hudum-deux nécropoles (Spinei, Popovici 1985, p. 76, 77, Fig.2/9, Spinei, Popovici 1988, p. 240, 246), Vornicenii 
Mari (Matei, Emandi 1980, p. 588, Matei, Emandi 1982, p. 126, 187, Fig.21/3, 4. Dans le texte il s'agit de M.11, mais dans l'illustration, de la page 187, il est marqué avec le numéro 18. Dans le texte, M.18 ne correspond pas comme description avec l'illustration).

Dans la Dobroudja, des pareilles sépultures ont été découvertes à Păcuiul lui Soare (Nous remercions Mme O. Damian pour les informations.), Garvăn (Ştefan, Barnea, Comşa, Comşa 1967, p. 371, 372, Fig. 196/2-3), Nufăru (Damian 1993, p. 85, 86, Fig.4/2, 3, p. 88, Fig.6/1, p. 89, Fig.7/4, p. 90, 91, 109, 111, 112), Enisala, Isaccea (Vasiliu 1984, p. 108, 109. Cette position des bras et ses sous variantes, a été mise à une population venu sur le territoire actuel de la Roumanie et qui a gardé des anciennes traditions d'enterrement).

En Transylvanie, ont été signalées de même des sépultures dans les quelles les défunts ont été déposés avec l'un ou les deux bras fléchis du coude, avec les paumes sur les épaules (Mârza, Burchinoiu 2004, Pl. IX, S IA. Plan (1), M.7). Ici les sépultures en grande partie sont plus anciennes, mais elles sont aussi très rares (Vasiliu 1984, p. 108, Luca, Pinter 2001, p. 99, 245, Taf.64/1, 4, p. 100). Pour le stade actuel de la recherche, la présence de pareilles sépultures dans les nécropoles du type Ciumbrud, en Slovaquie ou Hongrie (Kiss 1983, p. 157, 71.ábra) doit être analysé avec grande attention.

Parce que au nord du Danube l'habitude de la déposition du défunt dans sa tombe avec un ou les deux bras fléchis du coude et avec la paume sur l'épaule ou au cou est le mieux observable du point de vue chronologique, planimétrique et du point de vue des habitudes d'enterrement dans les cimetières étudiés au Banat, nous sommes d'avis qu'il est nécessaire faire une parallèle entre les découvertes d'ici et celles du site de Vadul Anei. Cela d'autant plus que au Banat, on peut établir aussi une chronologie de la pénétration des bogomiles ou des principaux moments quand ceux-ci on pénétraient ou ils on activaient (Oța 1998, p. 113-123).

Dans le territoire voisin, au Banat, des sépultures avec les bras étaient fléchis du coude, avec les paumes dans la région du cou, sur les épaules ou sur les clavicules (Pour le territoire du Banat, nous avons distinguer cinq positions fondamentales des bras des défunts en rapport avec le corps, démarquées alors avec des lettres, de $\mathrm{A}$ à $\mathrm{E}$. La variante $\mathrm{A}$ - les bras à côté du corps. La variante $\mathrm{B}-$ les bras à côté du corps, mais les paumes sur le bassin. La variante $\mathrm{C}-$ les bras sur l'abdomen. La variante $\mathrm{D}$ - les bras sur la boite thoracique. $\mathrm{La}$ variante $\mathrm{E}$ - les bras fléchis du coude, avec les paumes sur le cou, sur les clavicules ou épaules. A part cela il y a aussi des sousvariantes, obtenues des combinassions des variantes. Mais pour chaque sépultures on doit analyser si il s'agit de sous-variante ou si ce n'est pas le cas d'accidents pendant l'enterrement (Oța 1998, p. 113-123, Oța 2004, p. $81,85,88,93,94) . L a$ bas sont identifies pareilles sépultures en 14 nécropoles: IlidiaCetate-M.1, 3, 8, 11, 17, 45, 53, 54, 80 (Matei, Uzum 1972, p. 555-559), Gornea-TârchevişteM.6, 22, 24, 37/38, 50, 53 (Uzum 1975, p. 131142), Ciclova Română-Morminți-M.5, 8, 13, 19, 21, 23 (Uzum, Țeicu 1981, p. 211-216), Gornea-Căunița de Sus-M.5, 23, 24, 44, 60 (Țeicu, Lazarovici 1996, Lazarovici, Maxim, Țeicu, Oprinescu 1993, p. 295-319, Uzum 1981, p. 181-210), Cuptoare-Sfogea-M.108, 128, 209, 221 (Uzum 1987, p. 281-315), Gornea-Pod Păzărişte-M.1， 5, 7 (Țeicu, Lazarovici 1996, p. 93, Fig. 52, 94, Fig. 53, P1. 16, 17; Uzum 1974, p. 160-161, Pl. XXV/b, XXVI/a; Uzum 1975, p. 140; Uzum 1980, p. 130, Fig. 12, p. 131), Gornea-Ogaşul lui Udrescu-M.16, 23, 25 (Uzum 1975, p. 140), Ilidia-Oblița-M.23, 24 (Matei, Uzum 1972, p. 555-559, Uzum 1979, p. 387-389, Uzum, Lazarovici 1971, p. 157-162), Nicolinț-Râpa Galbenă-M.5 (Radu, Țeicu 2003, p. 212-213. Nous remercions à Mme A. Radu et au monsieur D. Țeicu pour le matériel inédit mis à notre disposition.), Pojejena-Nucet-M.8 (Uzum 1974, p. 159-164, Țeicu 1998, p. 129-130, Țeicu 1993, p. 239, 258, Uzum, Lazarovici 1974, p. 48), Reşița-Ogăşele-M.40 (Țeicu 1993, p. 239-240, 245, 247, 248, 250, 258, 268, 271; Țeicu 1996 a, p. 5-20; Țeicu 1998, p. 124, 132, 136, 140,141, 144, 147, 153, 163, 172, 179, 192; Uzum, Țeicu 1983, p. 297-310), Cârnecea-Dealu Bisericii-M.16 (Țeicu 1993, p. 231; Țeicu 1995, p. 227-249; Țeicu 1996 c, p. 56-76; Țeicu 1998, p. 124, 131, 147, 177, 188, 
189), Berzovia-Pătruieni-M.3 (Țeicu 1996 (b), p. 38, Fig.4), Şopotu Vechi-Mârvilă-M.38 (Țeicu 2003, p. 28), de 43 sépultures (un est double). Tous les sites se trouvent sur l'actuel territoire du département de Caraş-Severin. Les sépultures ont été découvertes autant dans des nécropoles avec église, que sans. En ce qui concerne les défunts ayant les bras fléchis du coude et les paumes sur les clavicules ou au cou ont été émises deux hypothèses. D'après la première il s'agit de pratiques rituelles d'avant l'enterrement ayant des intentions contre les vampires et elle a été mise un liaison avec les croyances des slaves (Hanuliak 2000, p. 140, 141, Fig. 3/1-3). La deuxième hypothèse est celle que ces sépultures appartiennent a des personnes ayant les croyances des bogomiles et qui se sont répandu au nord du Danube spécialement dès le XI-e siècle (Cantacuzino 1979, p. 359-372, Oța 1998, p. 113-123, Oța 2000 , p. 166, Glück 1978, p. 189-197, Glück 1979, p. 243-279).

L'orientation des sépultures est: O-E 27 sépultures de huit nécropoles (Ilidia-CetateO-E: M.1, 3, 8, 11, 17, 45, 53, 54, 80, GorneaȚârchevişte-O-E: M.6, 22, 24, 37-38, 50, 53, Ciclova Română-Morminți-O-E: M.5, 8, 13, 19, Gornea-Pod Păzărişte-O-E: M.1, 5, 7, Cuptoare-Sfogea-O-E: M.209, 221, IlidiaOblița O-E: M.23, Pojejena-Nucet-O-E: M.8, Berzovia-Pătruieni-O-E: M.3, NO-SE sept sépultures de trois nécropoles (Gornea-Căunița de Sus-No-SE: M.5, 24, 44, 60, Ciclova Română-Morminți-NO-SE: M.23, CârneceaDealu Bisericii-NO-SE: M.16), SO-NE-deux sépultures de deux nécropoles (Reşiţa-Ogăş̧eleSO-NE: M.40, Nicolinț-Râpa Galbenă: M.5), et pour autre six sépultures de trois nécropoles elle n'est pas connue (Gornea-Ogaşul lui Udrescu- inconnue pour M.16, 23, 25, Cuptoare-Sfogea- inconnues pour M.108 et 128 et Ilidia-Oblița- inconnues au M.24). Pour cette position des bras, prédomine l'orientation O-E (27 sépultures), suivant NO-SE (sept) et SO-NE (deux). Pour six sépultures l'orientation est inconnue.

L'analyse des sous-variantes (A l'analyse des sous-variantes, en ce qui concerne leur dispersion, est offerte pour le territoire du Banat, ce qui ne signifie pas qu'elle ne peuvent pas être rencontrées aussi dans d'autres régions du sud-est de l'Europe), a cause de la position différentes des bras a nécessité une étude spéciale pour démontrer s'il s'agit de pareilles pratiques ou sont des accidents produits pendant l'enterrement. Cela suppose l'étude du rapport avec les sépultures des variantes possibles de la quelle dériverait aussi la position dans certains cas dans les nécropoles.

La sous-variante $A E$ (une main au long du corps, et l'autre fléchis du coude et ayant la paume sur l'épaule ou sur le cou). On sais qu'elle a apparu dans trois nécropoles en trois sépultures, par un à Svinița- Km. fluvial 1004 (Boroneanț 1985, p. 113), Vojlovica-Humka Azotara (Stanojev 1989, p. 40, 41, 42, Fig.210) et Şopotu Vechi-Mârvilă (Țeicu 2003, p. 26). Toutes sont du sud du Banat. Dans aucunes de ces nécropoles le nombre des sépultures $\mathrm{AE}$ n'est relevant. Le plus probable elles sont des accidents d'enterrement, les défunts appartenant à la variante $\mathrm{E}$ ou aux sousvariantes dérivées d'elle.

La sous-variante $B E$ (une main avec la paume sur le bassin, et l'autre fléchis du coude avec la paume sur le cou ou sur l'épaule). On a trouvé huit pareilles sépultures dans cinq nécropoles: Gornea-Căunița de Sus - trois, Cuptoare-Sfogea - un, Hodoni-Pocioroane - un (Bejan, Moga 1979, p. 155-168, Draşovean, T,eicu, Muntean 1996, p. 36, 38, 41, 46, 48, 49, 52, 54, 133, Pl.LV), Obreja-Sat Bătrân-M.25 (TTeicu, Rancu 2003, p. 106-123; Țeicu, Rancu 2003, p. 455-467), Ciclova Română-MormințiM.22 (Uzum, Țeicu 1981, p. 211-216, Țeicu 1993, p. 231). Comme suite de l'analyse de la sous-variante dans chaque nécropole $d u$ territoire du Banat historique, nous sommes arrivé à la conclusion que la sous-variante $\mathrm{BE}$ a un caractère local, et elle est typique pour les nécropoles de la zone du sud-est du Banat. L'emplacement des nécropoles n'a pas de relevance dans ce cas. De ces nécropoles, seulement à Obreja-Sat Bătrân a été découvert un monument de cult.

Les sous-variantes $\mathrm{CE}$ et $\mathrm{DE}$ ont été analysées séparément, en chaque nécropole. $L a$ sous-variante CE (une main sur l'abdomen, et l'autre fléchis du coude, avec la paume sur la clavicule) a été surpris en 15 sépultures de six nécropoles (Ciclova Română-Morminți - cinq, 
Cârnecea-Dealu Bisericii - quatre, CuptoareSfogea - deux, Reşița-Ogăşele - deux, GorneaȚârchevişte - un, Obreja-Sat Bătrân - un), toutes du sud-est du Banat.

La sous-variante $D E$ (une main sur le thorax, et l'autre fléchis de coude avec la paume sur l'épaule ou le cou) a été surprise en neuf nécropoles contenant un nombre de 18 sépultures (Cuptoare-Sfogea - six, Obreja-Sat Bătrân - trois, Nicolinț - deux, Gornea-Căunița de Sus - deux, Gornea-Ţârchevişte - un, Pod Păzărişte - un, Ilidia-Oblița - un, SzöregHomokbánya - un, Vojlovica-Humka Azotara un). Les deux sous-variantes doivent être analysées ensemble parce que les positions $C$ et $\mathrm{D}$ des bras pourraient avoir la même signification. De même on ferra une comparaison avec les sépultures de la variante E.

Elles se trouvent dans la zone du SE du Banat à peu près sans exception. Des cas isolés on a trouvé seulement à Szöreg-Homokbánya (Bálint 1991, p. 93, 91, P1.XXX, p. 92, Pl.XXXI/16-21. Nous devons mentionner que dans cette sépulture on a découvert comme inventaire funéraire deux bagues décorées sur le chaton avec une étoile à cinq coins, considérée comme le signe des gnostiques) et Vojlovica-Humka Azotara.

L'orientation des sépultures avec les bras en position $\mathrm{CE}$ est la suivante: O-E (six sépultures de trois nécropoles: Ciclova Română-Morminți-O-E (M.9, 12, 18), Cuptoare-Sfogea-O-E (M.230, 264), ObrejaSat Bătrân-O-E (M.30), NO-SE pour cinq sépultures de trois nécropoles: Cârnecea-Dealu Bisericii-NO-SE (M.19, 23), Ciclova RomânăMorminți-NO-SE (M.20, 22), Gornea-Căunița de Sus-NO-SE (M.40), SO-NE chez deux sépultures de deux nécropoles: CârneceaDealul Bisericii-SO-NE (M.7), Reşița-OgăşeleSV-NE (M.26), N-S chez deux sépultures de deux nécropoles: Cârnecea-Dealu Bisericii (M.2), Reşița-Ogăşele (M.13).

L'orientation des sépultures avec les bras en position DE est la suivante: O-E pour huit sépultures de sept nécropoles: Obreja-Sat Bătrân-O-E (M.18 et 22), Gornea-ȚârchevişteO-E (M.33), Pod Păzărişte-O-E (M.3), Căuniţa de Sus-O-E (M.29), Ilidia-Oblița-O-E (M.34), Vojlovica-Humka Azotara-O-E (M.14), Cuptoare-Sfogea-O-E (M.225), NO-SE pour deux sépultures de deux nécropoles: CuptoareSfogea-NO-SE (M.51), Szöreg-HomokbányaNO-SE (M.38). Pour autre six sépultures de deux nécropole elle est inconnue: CuptoareSfogea - inconnue (M.4, 15, 94, 150, 306), Obreja-Sat Bătrân - inconnue (M.10).

Pour le cas de la sous-variante CE les sépultures en ont des divers orientations: O-E six, NO-SE - cinq, N-S - deux, SO-NE - deux. Pour la sous-variante DE les orientations sont: O-E - sept, NO-SE - deux, inconnues - cinq.

A Cârnecea-Dealu Bisericii, Ciclova Română-Morminți et Reşița-Ogăşele nous pouvons parler d'une sous-variante CE.

$\mathrm{La}$ position $\mathrm{DE}$ parait être pratiquée seulement à Cuptoare-Sfogea, Nicolinț, Obreja-Sat Bătrân et Gornea-Căunița de Sus. Pour les autres cas, sois qu'i s'agit des sousvariantes $\mathrm{CE}$ et $\mathrm{CD}$, sois qu'ils sont plus tôt des cas isolés, la plus grande partie des sépultures faisant part de la variante E (Ciclova RomânăMorminți, Ilidia-Cetate, Oblița, Gornea-PodPăzărişte et Țârchevişte, Nicolinț).

La position $\mathrm{CE}$ - peut être sous-variante à Ciclova Română-Morminți et CârneceaDealul Bisericii. La position DE a apparu prédominante au SE, mais aussi au N. Elle est une sous-variante seulement à Cuptoare et peut être à Gornea-Căuniţa de Sus (!?). Si les deux sous-variantes avaient en général la même signification, nous pouvons dire qu'elles sont caractéristiques pour la région du sud-est du Banat et nous pouvons augmenter le nombre de nécropoles dans le quel elles apparaissent comme habitude d'enterrement. Ainsi, nous pouvons dire qu'elle été pratiquée aussi à Cuptoare-Sfogea, Obreja-Sat Bătrân et probabil la Nicolinț-Râpa Galbenă.

Les positions $\mathrm{CX}$ et $\mathrm{DX}$ sont typiques pour la zone du SE, mais elles apparaissent aussi au N, isolées. Il s'agit de la même habitude comme dans les variantes AX et BX.

La position EX a apparu au sud et elle a été une pratique habituelle pour le cas des nécropoles de Şopotu Vechi-Mârvilă et Vojlovica-Humka Azotara. Un cas a été découvert aussi à Nicolinț (enfant) et un autre à Caransebeş-Măhala (Iaroslavschi 1975, p. 361, 362, Fig.6, p. 363, Fig.8/4). 
$\mathrm{Au}$ sud du Danube, des pareilles sépultures qui ont eu l'une ou les deux mains fléchis du coude et les paumes sur les épaules ou vers la zone de la clavicule ont été découvertes à Mačvanska Mitrovica: M.30 (Ercegović-Pavlović 1980, p. 29-30, Pl.V), M.214 (Ercegović-Pavlović 1980, p. 28, Pl.IV), M.70 (Ercegović-Pavlović 1980, p. 25, Pl.XXXV/4), Trnjane: M.125, 228, 80, 192, 373, 337 (Marjanović-Vujović 1984, p. 64-65, Fig.146), Brza Palanka M.6 (ErcegovićPavlović, Minić 1984, Fig.173), une nécropole à $4 \mathrm{~km}$ sud-est de Brza Palanka (Janković 1984, p. 200, Fig.196/a-b), Vajuga-Pesak M.2, 4, 31, 34, 59, 63, 81, 100 (Marjanović-Vujović 1986, p. 194, 195, 196, 197, 201, Planul II), Korbovo-situl Pesak M.3 (Radojčić 1986, p. 140, Fig.4), Vajuga-Korbovo (Krstić 1986, p. 151, 153, Fig.2/3, Pozamište M.10, 23 (Ercegović-Pavlović, D. Minić, 1986, p. 349, 350, 354, Planul II), Donićko Brdo (Petrović 1962-1963, p. 278, Fig.11, p. 280, Fig.19), Niš M.32, 36, 42, 72, 74 (Ercegović-Pavlović 1977, p. 96, 98). Des pareilles positions des bras des défunts ont été découvertes aussi dans la nécropole de Vukovar-Lijeva Bara, en Croatie M.92, 331, 315, 440 (Demo 1996, p. 73, 74, 76, 81, 83, 84). Dans la Crişana, au nord du Mureş, dans la nécropole de CladovaII, dans la nef de l'église a été découverte une sépulture avec les paumes sur le cou (recherches V. Boroneanț, P. Hurezan, P. Hügel et S. Oța en 1995).

Pour cette situation nous pressentons quelques aspects qui nous paraissent relevants. Par exemple, dans les nécropoles du sud de l'ancienne Yougoslavie, où l'orthodoxie s'est imposée d'une manière assez dure, la plus grande partie des inhumés ont eu les bras mis sur l'abdomen ou sur le thorax, dès le commencement. La même situation on l'observe, en bonne mesure, dans les milieux urbains du nord du Danube, comme par exemple à Caransebeş-Centre, où la plus grande partie des défunts ont eu les avant-bras sur le thorax. L'observation est en bonne partie valable aussi pour les squelettes découverts tout près des églises des monastères. Pour ces dernières deux situations, on doit supposer que l'église a imposé certaines règles de déposition des morts dans la terre, chose moins représentative pour le milieu rural. D'autre part, dans les établissements rurales, on constate une grande diversité des habitudes de la déposition des mains des morts, depuis les X-e - XI-e siècles jusque même au XV-e siècle. Cela nous fait croire que la bas ont persisté un temps plus long certaines pratiques de l'époque antérieure à la chrétienté (pour notre cas des populations des steppes - magyars, khazars, pétschénégues, coumans, slaves), ou d'une époque quand l'église n'a pas réussi a s'imposer clairement en ce qui concerne les différentes communautés, pour pouvoir changer fondamentalement les anciennes pratiques. A ceux-ci on doit ajouter aussi dès la fin du XI-e siècle et du commencement du XII-e d'une pénétration massive d'autres habitudes d'enterrement (au Banat), c'est-à-dire de celle liée des bras fléchis du coude des défunts et la mise des paumes sur les clavicules ou sur les épaules. Cette habitude a été considérée comme étant en liaison avec les pratiques funéraires des hérétiques bogomiles. Pour l'époque ancienne, en spécial des IX-e - X-e siècles, en Slovaquie, cette habitude rarement rencontrée a été considérée comme une pratique contre les vampires des populations slaves. Au Banat la position E des bras et éventuellement ses sous-variantes ont été longtemps utilisées, étant attestée du point de vue archéologique jusqu'à la fin du XV-e siècle.

En tout, de l'étude des nécropoles où on a découvert des pareils complexes funéraires, on peut tirer quelques observations générales. Une première est le fait que les morts n'occupaient une certaine position dans la nécropole. Ce type d'inhumation peut être rencontré autant chez des adultes (mâles ou femmes), que chez des enfants. Non les deux ou tous les membres d'une famille sont enterrées dans cette manière. Les pièces d'inventaire récupérées sont similaires avec celles des autres sépultures de la nécropole.

En général, la littérature roumaine concernant l'hérésie des bogomiles est assez pauvre et contradictoire (Nous rappelons seulement les plus neuves opinions, sans faire mention de toute la littérature. Culianu 1995, p. 247-267, Culianu 1998, p. 287-308; à voir aussi 
la bibliographie donnée; Rădvan 2004, p. 258259). La plus grande partie est d'une nature théologique ou philosophique. Seulement d'une petite mesure nous sommes en face d'études rédigées par les archéologues ou les historiens. Les derniers, avec des petites exceptions, se gardent en général d'attribuer certains complexes funéraires à une population hérétiques, indifférent de son origine (à voir les notes 5 et 37 . Les seules exceptions ont été faites par G. Cantacuzino, Gh. I Cantacuzino, E. Glück et S. Oța.).

$\mathrm{Du}$ point de vue des interprétations des historiens roumains concernant le problème des hérétiques dans l'espace actuel de la Roumanie ont existé diverses variantes. Par exemple, A. Balotă, considère que le bogomilisme représente plus tôt une culture apparue sur le territoire actuel de la Bulgarie, ,plus proche des masses populaires, de leurs aspirations, de leurs préoccupations". Pendant le temps, "...sous la pression de l'idéologie officielle chrétienne de l'état et de l'église féodale, il a reçu une aspect chrétien avec une teinte ...hostile envers la culture des grands féodaux, du haut clergé et des monastères" (Balotă 1964, p. 46-47). Les études de l'époque d'après la guerre et jusqu'en 1989 en bonne partie ont essayer a justifier la lutte de la population contre les feudaux et contre l'église même si sont reconnues les conjectures qui ont abouti à l'apparition de l'hérésie au sud du Danube.

D'autres historiens se sont préoccupé du lieu d'où sont ils venu au nord du Danube, ainsi que des zones où ils se sont établi, comme par exemple les crassovins (Oța 1998, p. 113-123, Rădvan 2004, p. 258-261, Simu 1939, p. 26-27, Lacea 1924-1926 (1927), p. 353-370) et ceux de la zone de Braşov.

Sur le territoire de la Valachie, où ne parle pas d'un document exprès concernant l'immigration d'hérétiques bogomiles, mais on doit supposer que parmi les groupes de population colonisés ici du sud du Danube, il doit y avoir eu aussi des hérétiques. Des données exactes concernant les étapes d'émigration des serbes et des bulgares sur les territoires du nord du Danube proviennent des sources historiques tardives (Rădvan 2004, p. 259 , 260. Il s'agit, le plus probable, de réfugiés des XIV-e, XV-e et XVI-e siècles. D'après les sources, ceux-ci peuvent être localisés dans les zones de Braşov, Câmpulung, Râmnicu Vâlcea, Ocna Mare, Lereşti.). Si pour les XIV-e - XVIe siècles on peu par ci par la localiser les zones où ils se sont établi, pour les XII-e - XIII-e siècles, nous savons seulement qu'ils sont passé aussi au nord du fleuve comme suite des persécutions religieuses.

Les sources littéraires d'après le X-e siècle, rédigées au nord du Danube sont extrêmement de sommaires. En fait il n'y a que une seule, celle de l'évêque Gérard de Cenad, et elle date de la première moitié du XI-e siècle (Glück 1978, p. 189-197). Mais celle-ci ne fait pas des mentions concernant la modalité de la déposition du défunt dans la terre. Dans ces conditions l'identification en terrain des sépultures bogomiles est plus tôt hypothétique. $\mathrm{Si}$ au sud du Danube on considère que la fin du XVI-e siècle est la date supérieure quand sont signalés des éléments hérétiques encore actifs, pas la même chose est la situation au nord du fleuve. Normalement, eux ils non plus représenté une force, mais on peut surprendre leurs manifestations tardives.

$\mathrm{Au}$ XVII-e siècle leur présence est encore signalée du point de vue documentaire dans la zone montagneuse du Banat, à Caraşova (Tufescu 1941, p. 514, 522). L'auteur suggère que la population des villages craşoviens des Montagnes du Banat, doit être au moins en partie bogomile (Trîpcea 1957, p. 95), dans les régions de Lipova, Timişoara et de la Jenopole (Simu 1939, p. 35, 38, 39, 40, 41. L'auteur mentionne les hérétiques et les pauliciens). En général, les historiens considère qu'on devrait plus tôt les chercher du point de vue archéologique, pouvant être identifiés à l'aide du rituel spécifique d'enterrement ou par leurs monuments funéraires (Rădvan 2004, p. 260, Glück 1978, à voir les considérations concernant les complexes funéraires du sud du Banat). Probablement que la situation a été similaire aussi en Valachie, où sont signalées des pénétrations de populations serbe et bulgare.

Un premier élément qui a attiré l'attention des archéologues, consiste dans la position des bras des défunts dans leur sépulture. Une identification primaire a été celle de la déposition des bras fléchis du coude avec 
les paumes sur les épaules, sur le cou ou sur les clavicules. Mais cette pratique ne dit rien en ce qui concerne une éventuelle appartenance du défunt a une secte ou a une autre, seulement qu'il s'agit de certaines pratiques rituelles, d'autres que celles habituelles. Partant de cet élément, en correspondance avec les données historiques, nous avons essayé dans une étude plus ancienne de distinguer les étapes des pénétrations ou de manifestation de ces possibles hérétiques sur le territoire du Banat (Oța 1998, p. 113-123).

Un autre indice qui peut être un argument en faveur du fait que nous sommes en face de personnes qui auraient probablement des certaines connaissances concernant les religions dualistes serait les découvertes de complexes funéraires dans les quels on a trouvé des bagues décorées avec une pentagramme. Elles sont fréquentes aux X-e - XI-e siècles dans tout le sud-est de l'Europe et en Hongrie méridionale à Szöreg-Homokbánya-M.38, Kiszombor-BM.426, 396 (Bálint 1991, p. 93, 92, Pl.XXXI/19, 20, Fehér, Éry, Kralovánszky 1962, p. 48), en Bulgarie à Hisar (Džambov 1977, p. 56, 58), Dălgopol IX-e - XIV-e siècles (Lazarov 2001, p. 72, 168, no. cat. 174), en ancienne Yougoslavie, comme par exemple dansn M.102 de Donji Milanovac (Minić 1969, p. 244, Fig. 28), Mačvanska Mitrovica (Ercegović-Pavlović 1980, p. 59, Pl. XXVI/24).

En ce qui concerne la chronologie de ces sépultures, du territoire actuel de la Roumanie, nous pouvons dire que rarement on rencontre des pareils complexes funéraires depuis le XI-e siècle. Une fois avec le XII-e siècle, ce type d'enterrement ne constitue plus une rareté et même pour beaucoup de cimetière il est une constante. En fonction de la durée d'utilisation d'un cimetière, l'habitude d'un ou des deux bras fléchis avec les paumes sur les épaules ou sur le cou est relativement constante. La limite chronologique supérieure pour ces pratiques, est le XVII-e siècle.
Les futures recherches archéologiques pourrons apporter les futurs recherches archéologiques pourrons apport plus d'éclairage en liaison avec ces types de pratiques funéraires.

De même on doit dire que pendant le moyen age on a identifié dans l'Europe du sudest plusieurs hérésies de facture gnostique (A. Balotă parle, par exemple, des paterans de Bosnie et des babuns en Serbie). Comme suite des données archéologiques ou documentaires nous ne pouvons pas faire des différences entre les divers sectes, où elles se sont établi et quel habitudes funéraires ont elles pratiqué.

A l'étranger, même si la littérature est un peu plus riche, elle reprend en général les même sujets (De la nouvelle littérature mous pouvons mentionner les travaux de Stoyanov (1999), Anghelov 1980, Dragoslović 1979, 1982. A voir aussi la bibliographie). Du point de vue archéologique, les opinions sont divergentes en ce qui concerne l'identification des sépultures qui peuvent être attribuées à ces hérétiques. A un moment donné on leur a attribué spécialement les monuments funéraires de l'espace de l'ancienne Yougoslavie (Delaruelle 1967, p. 3637, Soloviev 1955 (1957), p. 162-165), pour que en suite on revienne et cette interprétation soit contestée (Miletić 1968, p. 3). 


\section{BIBLIOGRAPHIE}

Anghelov, D. 1980. Bogomilstvoto v Bulgaria, Sofia.

Bálint, Cs. 1991. Südungarn im 10. Jahrhundert, Budapeste.

Balotă, A., 1964. Bogomilismul şi cultura maselor populare din Bulgaria şi Țările Române, Romanoslavica, X, Bucurest.

Bejan, A., Moga, M. 1979. Necropola feudal timpurie de la Hodoni (jud. Timiş), Tibiscus, Timişoara, 5, p. 155-168.

Bona, P. 1993. Biserica medievală din Caransebeş, Reşiţa.

Boroneanț, V. 1985. Cimitirul feudal timpuriu de la Svinița Km. fluvial 1004, Drobeta, Drobeta-TurnuSeverin, 6, p. 111-118.

Cantacuzino, G. 1963. Unele probleme istorice privind aşezătile medievale muntene în lumina cercetărilor arheologica de la Cernica, SCIV, Bucureşti, 2, anul XIV, Bucurest, p. 361-394.

Cantacuzino, G. 1979. Renseignements nouveaux concernant les tombes de bogomiles découvertes in Roumanie et leur rituel funéraire, ZNM, Belgrade, IX-X, p. 359-372.

Cantacuzino, G. 1998. Considerații privind necropola din jurul bisericii vechii curți domneşti din Câmpulung, SCIVA, Tomul 49, 2, p. 181-193.

Cantacuzino, Gh., Trohani, G. 1981. Cercetările arheologice de la Cernica-Mănăstire, Cercetări Arheologice, Bucurest, IV, p. 200-239.

Coman, R., Rența, E., Matei, Gh., Oța, S. 2003. Raport de cercetare arheologică pe anii 2001-2003 la Oraşul de Floci (com. Giurgeni, Jud. Ialomița), Cercetări arheologice, Bucurest, XII, p. 45-56.

Culianu, I.P. 1995. Gnozele dualiste ale Occidentului, Bucarest.

Culianu, I.P. 1988. Arborele gnozei. Mitologia gnostică de la creştinismul timpuriu la nihilismul modern, Bucarest.

Damian, O. 1993. O necropolă medievală timpurie descoperită la Nufăru (jud. Tulcea), SCIVA, Tomul 44, 1, p. 81-113.

Delarouelle, C.E. 1967. Les avatars $d u$ catharisme $d u$ XIVe-XXe siècle, Archeologia, NovembreDecembre, p. 34-41.

Demo, ̌̌. 1996. Vukovar. Lijeva Bara, Zagreb.

Diaconescu, P., Mihăescu, G. 1982 (apărut 1986). Cercetări arheologice la Dumbrava, com. Ulmi, jud. Dâmboviţa, MCA, Vaslui, p. 253-261.

Dragoslović, D. 1979. Bogomilstvo na Balkanu i u Maloj Aziji. Vol I, Bogomilski rodonacalcini, Beograd.

Dragoslović, D. 1982. Bogomilstvo na Balkanu i u Maloj Aziji. Vol II, Bogomilstvo na pravoslavnom istoku, Beograd.

Draşovean, Fl., Țeicu, D., Muntean, M. 1996. Hodoni. Locuirile neolitice târzii şi necropola medievală timpurie, Reşiţa.

Drâmboianu, V. 1978. Săpăturile arheologice de salvare în necropola din punctul „,Balastieră” (Buzăuest), Mousaios. Studii şi cercetări de istorie locală, Buzău, II, p. 26-33.

Ercegović-Pavlović, S. 1976. Nécropole médiévale à Niš, Starinar, Beograd, XXVII, p. 83-100 şi T.I-XVI.

Ercegović-Pavlović, S. 1980. Les nécropoles romaines et médiévales de Maćvanska Mitrovica, Sirmium, XII, Beograd.

Ercegović-Pavlović, S., Minić, D. 1984. Brza Palanka.Secteur II-III.Fouilles de 1980 (Moyen Age), În: Cahiers des Portes de Fer, Beograd, II, p. 171-174.

Ercegović-Pavlović, S., Minić, D. 1986. Le site d'habitation et la necropole de Pozamište, În: Cahierd des Portes de Fer, Beograd, III, 346-361.

Glück, E. 1978. Câteva considerații preliminare privind lucrarea "Deliberatio" (sec. al XI-lea), Ziridava, Arad, X, p. 189-197.

Glück, E. 1979. Considerații privind izvoarele istorice scrise, referitoare la ducatul lui Ahtum (prima parte a secolului al XI-lea), Ziridava, XI, p. 243-279. 
Hanuliak, M. 2000. Burial Grounds-Source of Knowledge about the Great Moravian Period, În: Slovaks in the Central Danubian Region in the $6^{\text {th }}$ to $11^{\text {th }}$ century, Bratislava, p. 133-147.

Iaroslavschi, E. 1975. O villa rustica la Caransebeş, Banatica, Reşița, 3, p. 355-363.

Ioniță, I. 1962, Săpăturile de salvare de la Trifeşti, MCA, Bucarest, VIII, p. 733-739.

Ioniță, A. 2004. Morminte de călăreți la nordul Dunării de jos în sec. X-XIII, În: Prinos lui Petre Diaconu la 80 de ani, Brăila, p. 461-881, Fig. 1-7.

Janković, Đ. 1984, Le site Médiéval à l'embouchure de la Rivière Slatinska. Fouilles de 1980, În: Cahierd des Portes de Fer, Beograd, II, p. 199-200.

Kiss, A. 1983. Baranya megya X-XI. századi sírleletei, Budapest.

Krstić, D. 1986. Vajuga-Korbovo, În: Cahies des Portes de Fer, Beograd, III, p. 148-153.

Lacea, C. 1924-1926 (apărut 1927). Sânt în Transilvania aşezări de Români veniți din sudul Dunării sau nu sânt?, Dacoromania, IV, Cluj Napoca, p. 353-370.

Lazarovici, Gh., Maxim, Z., Țeicu, D., Oprinescu, A. 1993. Şantierul arheologic Gornea 1989, Banatica, Reşița, 12, I, p. 295-319.

Luca, S.A., Pinter, Z.K. 2001. Der Böhmerberg bei Broos/Orăştie. Eine Archäologie Monographie, Sibiu.

Marjanović-Vujović, G. 1984. Trnjane. Serbian necropolis (11th-13th century), Beograd.

Marjanović-Vujović, G. 1986. Vajuga-Pešac. La nécropole médiévale II, În: Cahiers des Portes de Fer, Beograd, III, p. 184-237.

Matei, M.D., Emandi, Em.I. 1980. Necropola feudal-timpurie de la Vornicenii Mari (Jud. Suceava), SCIV, Bucarest, 4, Tom.31, p. 585-597.

Matei, M.D., Emandi, Em.I. 1982. Habitatul medieval rural din Valea Moldovei şi din bazinul Şomuzului Mare. Secolele XI-XVII, Bucarest.

Matei, Şt., Uzum, I. 1972. Date noi în legătură cu biserica şi fortificația de la Ilidia, AMN, ClujNapoca, 9, p. 555-559.

Mârza, E., Burchinoiu, I. 2004. Biserica medievală din Sântimbru, în Bibliotheca Universitatis Apulensis, XI, Alba Iulia.

Miletić, N. 1968. Expoziția monumente funerare din Iugoslavia, Bucarest.

Oța, S. 1998. Mormintele bogomile din sudul Banatului (secolele XII-XV), AM, Reşiţa, II, p. 113-123.

Oța, S. 2000. Câteva considerații în legătură cu necropolele medievale rurale din sudul Banatului (sec. XII-XV), Banatica, Reşița, 15, p. 161-176.

Oța, S. Orizonturi funerare în Banatul istoric (secolele X-XIV), Lucrare de doctorat în manuscris, aflată la biblioteca Institutului de Arheologie ,V. Pârvan”.

Petrović, D. M. 1962-1963. Nécropole médiévale dans la localite Donićko Brdo à Gradac, Starinar, Beograd, XIII-XIV, p. 275-291.

Radojčić, N. 1986. Les fouilles du site «Pesak» a Korbovo en 1981, În: Cahiers des Portes de Fer, Beograd, III, p. 133-142.

Radu, A., Țeicu, D. 2003. 127. Nicolinț, com. Ciuchici, jud. Caraş-Severin, punct Daia Parte, Crăguieț, Râpa Galbenă, CCA, campania 2002, Bucarest, p. 212-213.

Rădvan, L. 2004. Oraşele din Țara Românească până la sfârşitul secolului al XVI-lea, Iaşi.

Rejholková, M. 1995. Das Gräberfeld von Čakajovce (9.-12. Jahrhundert). Analyse, Nitra-Budapesta.

Simu, T. 1939. Originea craşovenilor. Studiu istoric şi etnografic, Lugoj.

Soloviev, A.V. 1957. Le symbolisme des monuments funeraires bogomiles et cathares, În: Actes du Xe Congres nternational de Studes Byzantines, Istambul, p. 162-165.

Spinei, V., Popovici, R. 1985. Cercetările arheologice din necropola medievală de la Hudum, Jud. Botoşani, Arheologia Moldovei, Iaşi, X, p. 74-88.

Spinei, V., Popovici, R. 1988. Săpăturile arheologice din necropola medievală de la Hudum (1987), Arheologia Moldovei, Iaşi, XII, p. 233-247.

Stanojev, N. 1989. Nekropolen aus dem 10.-15. Jahrhundert in der Vojvodina. 712 Katalogabschnitte. Katalog 1, Novi Sad.

Stoyanov, Y. 1999. Tradiția ascunsă a Europei. Istoria secretă a ereziei creştine în Evul Mediu, Bucarest.

Ştefan, Gh., Barnea, I., Comşa, M., Comşa, E. 1967. Dinogeția. I. Aşezarea feudală timpurie de la Bisericuța Garvăn, Bucarest. 
Ştefănescu, A. 1981. Consemnări arheologice pe şantiere de construcții, Cercetări arheologice în Bucureşti, III, p. 265-278.

Tătulea, C.T. 1981. Cercetări în cimitirul medieval de la Portăreşti, Județul Dolj, Oltenia. Studii şi Comunicări, Craiova, III, p. 47-60.

Trâpcea, Th. N. 1957. Craşovenii ,o măruntă ” populație din țara noastră. De unde şi când au venit ?, Studii, anul X, Nr. 6, p. 93-101.

Trohani, Gh. 1982. Pagini din scrisori, pagini de arheologie. Din corespondența prof. Gheorghe Cantacuzino, Cercetări Arheologice, Bucureşti, V, p. 235-257.

Tufescu, V. 1941. O măruntă populație balcanică în Banat, Balcania, IV, p. 503-529.

Țeicu, D. 1989. O reşedință feudală românească la începuturile Reşiței Medievale, SCIVA, Bucureşti, Tomul 40, 1, p. 57-72.

Țeicu, D. 1991. Cercetări de arheologie în necropola medievală timpurie de la Şopotu Vechi-Mârvilă (jud. Caraş-Severin), Crisia, Oradea, 21, p. 307-310.

Țeicu, D. 1993. Necropole medievale (sec. X-XIV) din sudul Banatului, Banatica, Reşița, 12, I, 229-272.

Țeicu, D. 1995. Biserica medievală din Cârnecea, Banatica, Reşiţa, 13, p. 227-249.

(a) Țeicu, D. 1996. O reşedință feudală românească la începuturile Reşiței Medievale, A.S.M.B., Reşița, 1996, p. 5-20.

(b) Țeicu, D. 1996. Cercetări de arheologie medievală la Berzovia, A.S.M.B., Reşița, p. 37-47.

(c) Țeicu, D. 1996. Biserica medievală de la Cârnecea, A.S.M.B., Reşiţa, p. 56-76.

Ţeicu, D. 1998. Banatul montan în evul mediu, Timişoara.

(a) Țeicu, D. 1993. Necropola de la Şopotu Vechi, Studii istorice, Reşița, p. 23-60.

(b) Țeicu, D. 1993. Biserica satului dispărut Bizere, ${ }_{2}$ Studii Istorice, Reşița, p. 106-123.

Țeicu, D., Lazarovici, Gh. 1996. Gornea. Din arheologia unui sat medieval din Clisura Dunării, Reşița. Țeicu, D., Rancu, D. 1997. Obreja-Sat Bătrân, j. Caraş-Severin, CCA, Campania 1996, Bucureşti, p. 40-41.

Țeicu, D., Rancu, D. 2003. Cercetări de arheologie medievală pe Valea Bistrei, În: In memoriam Radu Popa. Temeiuri ale civilizației româneşti în context european, Bistrița Năsăud, p. 455-467.

Uzum, I. 1974. Două cimitire feudale timpurii de la Gornea şi Pojejena (jud. Caraş-Severin), Tibiscus, Timişoara, 3, p. 159-164.

Uzum, I. 1975. Cimitirul medieval de la Gornea-Țârchevişte, Banatica, Reşița, 3, p. 131-142.

Uzum, I. 1979. Săpăturile arheologice de la Ilidia (campania 1978), MCA, XIII, p. 387-389.

Uzum, I. 1981. Necropola feudal timpurie de la Gornea-Căunița de Sus (jud. Caraş-Severin), Banatica, Reşița, 6, p. 181-210.

Uzum, I. 1987. Considerații pe marginea cercetărilor din anii 1983-1985 în necropola feudală timpurie de la Cuptoare (com. Cornea, jud. Caraş-Severin), Banatica, Reşița, 9, p. 281-315.

Uzum, I. 1989. Ilidia, o reședință puțin cunoscută a cnezilor români din sudul Banatului, RMM-MIA, Bucureşti, 2, p. 39-44.

Uzum, I., Lazarovici, Gh. 1971. Aşezarea feudală Ilidia în lumina izvoarelor scrise şi a cercetărilor arheologice, Banatica, Reşiţa, 1, p. 157-162.

Uzum, I., Lazarovici, Gh. 1974. Descoperiri arheologice prefeudale şi feudale timpurii în zona superioară a Clisurii, Crisia, Oradea, 4, p. 47-50.

Uzum, I., Țeicu, D. 1981. Cercetările arheologice de la Ciclova Română (jud. Caraş-Severin), Banatica, Reşița, 6, p. 211-216.

Uzum, I., Țeicu, D. 1983. Precizări de ordin cronologic şi considerații istorice în legătură cu monumentul de arhitectură feudală de la Reşița-Ogăşele, Banatica, Reşița, 7, p. 397-310.

Vasiliu, I. 1984. Cimitirul feudal timpuriu de la Isaccea, Peuce, Tulcea, IX, p. 107-141.

\section{Silviu Oța}

Muzeul Național de Istorie a României

Calea Victoriei 12, sector 3, Bucuresti

030026 ROMÂNIA 